Original

\title{
Oral health status of mentally disabled subjects in India
}

\author{
Manish Jain ${ }^{1)}$, Anmol Mathur ${ }^{1)}$, Leena Sawla ${ }^{2)}$, Geeta Choudhary ${ }^{1)}$, Komal Kabra ${ }^{1)}$, \\ Prabu Duraiswamy ${ }^{1)}$ and Suhas Kulkarni ${ }^{1)}$ \\ ${ }^{1)}$ Department of Preventive and Community Dentistry, Darshan Dental College, Udaipur, India \\ ${ }^{2}$ Department of Otorhinolaryngology, SMS Medical College and Hospital, Jaipur, India
}

(Received 16 September 2008 and accepted 26 March 2009)

\begin{abstract}
The aim of the study was to determine the oral health status and investigate the association of oral health status with various socio-demographic (age, gender, parent's education, income) and clinical variables (aetiology for mental disability and IQ level) among mentally disabled subjects. The study sample comprised 225 mentally retarded subjects aged 12-30 years attending a special school in Udaipur, India. Caries status, oral hygiene status and periodontal status were assessed by DMFT Index, Simplified Oral Hygiene Index (OHI-S) of Greene and Vermillion and Community Periodontal Index, respectively. Chi-square test, one way analysis of variance (ANOVA), multiple linear stepwise regression analysis, and multiple logistic regression analysis were employed for statistical analysis. There was a statistically significant difference $(P=0.001)$ between all the age groups in all the variables of Oral hygiene index and DMFT index. The oldest age group had the highest scores for all the indices measured. Having Down's syndrome, parents with lower educational status and low I.Q. were the most important predictors for poor oral health status. The present study highlighted that the oral health status of this mentally retarded population was poor and was influenced by aetiology of the disability, I.Q. level, and parent's level of education. (J Oral Sci 51, 333-340, 2009)
\end{abstract}

Keywords: Oral hygiene; mentally retarded; Down's syndrome.

Correspondence to Dr. Manish Jain, Department of Preventive and Community Dentistry, Darshan Dental College and Hospital, Loyra, Ranakpur Road, Udaipur, Rajasthan313001, India Tel: +91-9414489459

Fax: +91-2942452273

E-mail: manrescommunity@yahoo.com

\section{Introduction}

Literature on the dental management of handicapped subjects is scarce compared with that of the normal child. Until recent years, the management of handicapped subjects was not even mentioned in the undergraduate curriculum of most dental schools in different parts of the world.

The disabled comprise a substantial section of the community and it is estimated that there are about 500 million people with disabilities worldwide (1). The recent NSSO report suggests that the number of disabled persons in the country is estimated to be 18.49 million, accounting for about $1.8 \%$ of the total population, while the mentally retarded population amounted to 0.44 million individuals (2). Mental retardation has been defined by the American Association of Mental Deficiency (AAMD) as a deficiency in theoretical intelligence that is congenital or acquired in early life. The AAMD classifies retardation into four categories according to intelligence quotient (IQ): mild, moderate, severe or profound retardation. An individual is classified as having mild mental retardation if his or her IQ score is $50-55$ to about 70; moderate retardation, IQ 35-40 to 50; severe retardation, IQ 20-25 to 35; and profound retardation, IQ below 20-25 (3). Developmental disabilities can develop due to a variety of conditions which include cerebral palsy, Down's syndrome, mental retardation, autism, seizure disorders, hearing and visual impairments, congenital defects, and even social or intellectual deprivation (4).

Dental caries is the most prevalent disease among mentally retarded children worldwide and "dental treatment is the greatest unattended health need of the disabled"(5). Some of the most important reasons may be inadequate recall systems, practical difficulties during treatment sessions, socioeconomic status, underestimation of 
treatment need or pain, communication problems and bad cooperation (5-9). Many published studies have reported relatively poor oral hygiene and high levels of periodontal disease in mentally challenged children (10-11) and in a questionnaire survey, Randell et al. found that children with Down's syndrome had poorer dental health practices than normal children do (12). Individuals with Down's syndrome demonstrate a high prevalence of periodontal diseases $(13,14)$. A review of literature on dental abnormalities and diseases in persons with Down's syndrome consistently showed increased frequency of periodontitis compared with that of other patients with mental retardation $(15,16)$ as well as compared with that of the general population $(17,18)$.

All the abovementioned studies have extensively analyzed the mentally retarded population with many variables, but in a developing country like India further research in this field is required. Therefore, the purpose of this study was to determine the oral health status and investigate the association of oral health status with various socio-demographic (age, gender, parent's education, income) and clinical variables (aetiology for mental disability and IQ level) among mentally disabled children attending a special school in Udaipur, India.

\section{Materials and Methods}

A cross-sectional descriptive survey was conducted in 254 mentally retarded subjects, aged 12-30 years, attending a Special Needs school in Udaipur city. Children and adolescents who were present at school on the days of the survey were included and those who were uncooperative had severe detrimental systemic disorders like cardiac defects and with unknown aetiology for mental disability were excluded. Nine subjects were absent, 16 did not cooperate and 4 were systemically ill. The final sample thus consisted of 225 mentally retarded subjects. Informed consent of the parents or guardians and school authorities was obtained before the subjects were included in the study. The study was approved by the Ethical Committee for Research of the Darshan Dental College and Hospital, Udaipur.

Prior to the dental examination, demographic information was recorded for each subject: age, gender and education and income of parents. Clinical assessment of oral hygiene status was done by two examiners with a mouth mirror and No. 23 explorer according to criteria of simplified oral hygiene index by Green and Vermilion (19). Periodontal status was assessed by Community Periodontal Index (20); children below the age of 15 years were assessed for bleeding and calculus only as recording of periodontal pockets would be overestimated in this population because of false pockets. The two examiners were calibrated before the survey. The inter-examiner variability was tested and the weighted kappa statistic was $90.3 \%$. Dental caries was recorded according to the $\mathrm{WHO}$ caries diagnostic criteria using the mouth mirror and CPI probe. Intelligence Quotient level for each subject was assessed using the Weschler intelligence scale for children (WISC) of the 12-16 years age group and Weschler adult intelligence scale for above 16-year-olds. The mean and standard deviation were used to describe the patterns of oral hygiene and caries status in all groups. Chi-square tests were used to test the differences in frequencies between the age groups and prevalence of periodontal disease. One-way Analysis of Variance (ANOVA) was used to test the differences in the mean scores of oral hygiene, caries and periodontal indicators. Multiple linear stepwise regression analysis was employed to analyze the association of various sociodemographic and clinical variables with caries, oral hygiene and periodontal indicators. Multiple Logistic regression analysis was executed to test the associations of various independent variables with the caries, oral hygiene and periodontal disease status. The effect of each independent variable was assessed adjusting for that of all others in the model. For cross tabulation and logistic regression analysis, variables were forced into the model by dichotomizing the continuous data. Data were analyzed using the Statistical Package for Social Science (SPSS), Version-11.0.

\section{Results}

Table 1 illustrates the general profile of the study population. There was a difference in the distribution of subjects according to age group, with only $5.3 \%$ of the subjects belonging to the 26-30 year age group. There was also unequal gender distribution with males comprising $77.3 \%$ of the total sample. Only $58.7 \%$ of the subjects used a toothbrush for cleaning the teeth and $41.3 \%$ had never used a brush. Poor oral hygiene status was exhibited in $37.3 \%$ of the study population. $37.3 \%$ were severely mentally retarded and $60 \%$ of the subjects had cerebral palsy. None of the subjects exhibited deep periodontal pockets but shallow pockets were present in $22.7 \%$ subjects. More than half $(53.3 \%)$ of the population belonged to middle class group.

Table 2 shows the mean DMFT and mean DMFS scores in various age groups. There was a statistically significant difference $(P=0.002)$ between all the age groups for DMFT. The oldest age group had the highest DMFT and DMFS score, which was 2.75 and 3.25, respectively. There was a definite trend where mean scores for all the indices gradually increased with an increase in age.

Table 3 compares the Debris index (DI), calculus index 
Table 1 General profile and background characteristics of the study population

\begin{tabular}{|c|c|c|c|c|c|c|}
\hline \multirow[t]{3}{*}{ Items } & \multicolumn{4}{|c|}{ Sex } & & \\
\hline & \multicolumn{2}{|c|}{ Male } & \multicolumn{2}{|c|}{ Female } & \multicolumn{2}{|c|}{ Total } \\
\hline & $\mathrm{N}$ & $\%$ & $\mathrm{~N}$ & $\%$ & $\mathrm{~N}$ & $\%$ \\
\hline \multicolumn{7}{|l|}{ AGE:- Years } \\
\hline $12-15$ & 93 & $41.3 \%$ & 33 & $14.6 \%$ & 126 & $56 \%$ \\
\hline $16-20$ & 51 & $22.6 \%$ & 12 & $5.3 \%$ & 63 & $28 \%$ \\
\hline $21-25$ & 24 & $10.7 \%$ & 0 & $0.0 \%$ & 24 & $10.7 \%$ \\
\hline $26-30$ & 06 & $2.6 \%$ & 6 & $2.6 \%$ & 12 & $5.3 \%$ \\
\hline \multicolumn{7}{|c|}{ Oral Hygiene Practice:- } \\
\hline Use brush & 102 & $45.3 \%$ & 30 & $13.3 \%$ & 132 & $58.7 \%$ \\
\hline Don't use brush & 72 & $32.0 \%$ & 21 & $9.3 \%$ & 93 & $41.3 \%$ \\
\hline \multicolumn{7}{|l|}{ OHI-S } \\
\hline Good & 28 & $12.4 \%$ & 14 & $6.2 \%$ & 42 & $18.7 \%$ \\
\hline Fair & 75 & $33.3 \%$ & 24 & $10.7 \%$ & 99 & $44.0 \%$ \\
\hline Poor & 72 & $32 \%$ & 12 & $5.3 \%$ & 84 & $37.3 \%$ \\
\hline \multicolumn{7}{|l|}{ Periodontal Status } \\
\hline Healthy 0 & 42 & $18.6 \%$ & 9 & $4.0 \%$ & 51 & $22.7 \%$ \\
\hline Bleeding 1 & 51 & $22.6 \%$ & 15 & $6.6 \%$ & 66 & $29.3 \%$ \\
\hline Calculus 2 & 39 & $17.3 \%$ & 18 & $8.0 \%$ & 57 & $25.3 \%$ \\
\hline $\begin{array}{l}\text { Shallow- } \\
\text { Pocket }\end{array}$ & 42 & $18.6 \%$ & 9 & $4.0 \%$ & 51 & $22.7 \%$ \\
\hline \multicolumn{7}{|c|}{ Intelligence quotient(I.Q.):- } \\
\hline Mild & 26 & $11.5 \%$ & 1 & $0.44 \%$ & 27 & $12 \%$ \\
\hline Moderate & 35 & $15.5 \%$ & 4 & $1.7 \%$ & 39 & $17.3 \%$ \\
\hline Severe & 60 & $26.6 \%$ & 24 & $10.6 \%$ & 84 & $37.3 \%$ \\
\hline Profound & 53 & $23.5 \%$ & 22 & $9.7 \%$ & 75 & $33.3 \%$ \\
\hline \multicolumn{7}{|l|}{ Education of father } \\
\hline Secondary & 51 & $22.6 \%$ & 12 & $5.3 \%$ & 63 & $28.0 \%$ \\
\hline Senior secondary & 10 & $4.4 \%$ & 2 & $0.8 \%$ & 12 & $5.3 \%$ \\
\hline Under graduation & 71 & $31.5 \%$ & 16 & $7.11 \%$ & 87 & $38.7 \%$ \\
\hline Post graduation & 42 & $18.6 \%$ & 21 & $9.3 \%$ & 63 & $28.0 \%$ \\
\hline \multicolumn{7}{|c|}{ Education of Mother } \\
\hline Secondary & 58 & $25.7 \%$ & 14 & $6.2 \%$ & 72 & $32.0 \%$ \\
\hline Senior secondary & 14 & $6.2 \%$ & 1 & $0.4 \%$ & 15 & $6.7 \%$ \\
\hline Under graduation & 56 & $24.8 \%$ & 19 & $8.4 \%$ & 75 & $33.3 \%$ \\
\hline Post graduation & 46 & $20.4 \%$ & 17 & $7.5 \%$ & 63 & $28.0 \%$ \\
\hline \multicolumn{7}{|c|}{ Mentally Retarded Type :- } \\
\hline Down's syndrome & 73 & $32.4 \%$ & 17 & $7.5 \%$ & 90 & $40 \%$ \\
\hline Cerebral palsy & 101 & $44.8 \%$ & 34 & $15.1 \%$ & 135 & $60 \%$ \\
\hline \multicolumn{7}{|c|}{ Socio economic status } \\
\hline Very poor & 35 & $15.5 \%$ & 7 & $3.1 \%$ & 42 & $18.7 \%$ \\
\hline Poor & 8 & $3.5 \%$ & 4 & $1.7 \%$ & 12 & $5.3 \%$ \\
\hline Middle class & 87 & $38.6 \%$ & 33 & $14.6 \%$ & 120 & $53.3 \%$ \\
\hline Higher & 44 & $19.5 \%$ & 7 & $3.1 \%$ & 51 & $22.7 \%$ \\
\hline
\end{tabular}

(CI) and oral hygiene index (OHIS) mean scores at various age groups amongst the study subjects. There was a statistically significant difference $(P=0.001)$ between all the age groups for Oral hygiene index. The oldest age group had the highest scores for all the indices measured and mean scores for all the indices tended to increase gradually with an increase in age.

Table 4 shows the mean number of sextants with evidence of periodontal disease. Healthy sextants without any signs of periodontal disease were found in all younger age groups but contributed for 1.24 sextants overall. In the youngest age group, 1.71 sextants were found to be healthy, whereas in older age groups the corresponding value was 0.0 . The greatest periodontal destruction was manifested in the older age groups with 3.75 and 5.0 sextants presenting shallow periodontal pockets. Bleeding on probing was also commonly noted among all the age groups. There was a statistically significant difference between all the age groups.

Stepwise multiple linear regression analysis, which was executed to estimate the linear relationship between the dependent variables (DMFT, OHIS, CPI) and various 
Table 2 Mean DMFT and DMFS scores according to the age groups

\begin{tabular}{lccc}
\hline Age group & Number N & $\begin{array}{l}\text { DMFT* } \\
\text { Mean (SD) }\end{array}$ & $\begin{array}{l}\text { DMFS** } \\
\text { Mean (SD) }\end{array}$ \\
\hline 12-15 years & 126 & $1.50(2.13)$ & $1.90(2.58)$ \\
16-20 years & 63 & $2.61(2.40)$ & $3.19(2.76)$ \\
21-25 year & 24 & $2.63(2.16)$ & $4.75(4.20)$ \\
26-30 year & 12 & $2.75(1.86)$ & $3.25(2.14)$ \\
\hline Total & 225 & $2.01(2.26)$ & $2.64(2.96)$ \\
\hline ANOVA: $F^{*}-5.217 P-0.002, F^{* *}-8.30 P-0.000$
\end{tabular}

Table 3 Mean DI, CI and OHI-S scores according to the age groups

\begin{tabular}{llll}
\hline Age group & DI-S* & CI-S** & OHI-S*** \\
\hline 12-15 years & $1.65(0.65)$ & $0.90(0.71)$ & $2.56(1.15)$ \\
16-20 years & $1.85(0.78)$ & $1.30(1.00)$ & $3.15(1.70)$ \\
21-25 year & $1.62(0.71)$ & $1.24(0.98)$ & $2.87(1.56)$ \\
26-30 year & $2.29(0.70)$ & $1.79(0.77)$ & $4.08(1.29)$ \\
Total & $1.74(0.71)$ & $1.10(0.87)$ & $2.84(1.42)$ \\
\hline ANOVA: $F^{*}-3.79 P-0.011, \mathrm{~F}^{* *}-6.32 P-0.000, \mathrm{~F}^{*} * *-6.00 P-0.001$
\end{tabular}

Table 4 Mean number of sextants affected by periodontal conditions in various age groups

\begin{tabular}{lllll}
\hline Age group & $\begin{array}{l}\text { Healthy* } \\
0\end{array}$ & $\begin{array}{l}\text { Bleeding** } \\
\mathbf{1}+2+3\end{array}$ & $\begin{array}{l}\text { Calculus*** } \\
2+3\end{array}$ & $\begin{array}{l}\text { Shallow**** Pocket } \\
3\end{array}$ \\
\hline 12-15 years & $1.71(2.60)$ & $4.26(2.59)$ & $2.29(2.20)$ & $2.29(2.20)$ \\
16-20 years & $0.62(1.44)$ & $5.38(1.44)$ & $3.33(2.21)$ & $3.33(2.21)$ \\
21-25 year & $1.00(1.53)$ & $5.00(1.53)$ & $3.75(2.15)$ & $3.75(2.15)$ \\
26-30 year & $0.0(0.0)$ & $5.50(0.90)$ & $5.00(1.88)$ & $5.00(1.88)$ \\
Total & $1.24(2.22)$ & $4.72(2.21)$ & $2.88(2.30)$ & $2.88(2.30)$ \\
\hline ANOVA: $\mathrm{F}^{*}-5.180 P-0.002, \mathrm{~F}^{* *}-4.507 P-0.004, \mathrm{~F}^{* * *}-9.070$ & $P-0.000$, \\
$\mathrm{F}^{* * * *-9.070, P-0.000}$
\end{tabular}

Table 5 Step wise multiple linear regression analysis with DMFT as dependent variables

\begin{tabular}{lllll}
\hline Model & $\mathrm{R}$ & $\mathrm{R}^{2}$ & F Value & $P$ Value \\
\hline DMFT & & \multicolumn{4}{l}{} \\
1 & $0.275(\mathrm{a})$ & .076 & 18.29 & $0.000(\mathrm{a})$ \\
2 & $0.348(\mathrm{~b})$ & .121 & 15.31 & $0.000(\mathrm{~b})$ \\
3 & $0.385(\mathrm{c})$ & .148 & 12.81 & $0.000(\mathrm{c})$ \\
4 & $0.406(\mathrm{~d})$ & .165 & 10.84 & $0.000(\mathrm{~d})$ \\
\hline $\mathrm{a}$ & Predictors: (Constant), IQ & \\
b & Predictors: (Constant), IQ, MRTYPE & \\
c & Predictors: (Constant), IQ, MRTYPE, MEDU \\
$\mathrm{d}$ & Predictors: (Constant), IQ, MRTYPE, MEDU, AGE
\end{tabular}

independent variables, revealed that the best predictors in the descending order for DMFT index were I.Q, medical diagnosis, mother's education and age (Tables 5 and 6). I.Q, medical diagnosis, mother's education and age explained a variance of $16.5 \%$ with presence of IQ and education of mother contributing for $7.6 \%$ and $2.7 \%$ variance, respectively. It is evident from Tables 5 and 6 that all the independent variables were significantly associated with DMFT. In addition to those variables that were significantly associated with DMFT, oral hygiene practices were also associated with $\mathrm{OHI}-\mathrm{S}$, though oral hygiene practice provided a variance of $5.9 \%$ only. The best predictor for OHIS was IQ, which provide a variance of $13.1 \%$. For the community periodontal index, IQ level
Table 6 Step wise multiple linear regression analysis with OHIS and CPI as dependent variables

\begin{tabular}{|c|c|c|c|c|}
\hline Model & $\mathbf{R}$ & $\mathrm{R}^{2}$ & F Value & $P$ Value \\
\hline \multicolumn{5}{|l|}{$\mathrm{OHI}-\mathrm{S}$} \\
\hline 1 & $0.363(\mathrm{a})$ & 0.131 & 33.74 & $0.000(\mathrm{a})$ \\
\hline 2 & $0.416(\mathrm{~b})$ & 0.173 & 23.24 & $0.000(b)$ \\
\hline 3 & $0.464(\mathrm{c})$ & 0.215 & 20.18 & $0.000(\mathrm{c})$ \\
\hline 4 & $0.499(\mathrm{~d})$ & 0.249 & 18.26 & $0.000(\mathrm{~d})$ \\
\hline a & \multicolumn{4}{|c|}{ Predictors: (Constant), IQ } \\
\hline b & \multicolumn{4}{|c|}{ Predictors: (Constant), IQ, OHP } \\
\hline $\mathrm{c}$ & \multicolumn{4}{|c|}{ Predictors: (Constant), IQ, OHP, AGE } \\
\hline d & \multicolumn{4}{|c|}{ Predictors: (Constant), IQ, OHP, AGE, MRTYPE } \\
\hline \multicolumn{5}{|l|}{ CPI } \\
\hline 1 & $0.600(a)$ & 0.360 & 125.20 & $0.000(\mathrm{a})$ \\
\hline 2 & $0.623(b)$ & 0.388 & 70.37 & $0.000(\mathrm{~b})$ \\
\hline 3 & $0.646(\mathrm{c})$ & 0.418 & 52.89 & $0.000(\mathrm{c})$ \\
\hline \multirow[t]{2}{*}{4} & $0.659(\mathrm{~d})$ & 0.434 & 42.18 & $0.000(\mathrm{~d})$ \\
\hline & $0.667(\mathrm{e})$ & 0.445 & 35.10 & $0.000(\mathrm{e})$ \\
\hline a & \multicolumn{4}{|c|}{ Predictors: (Constant), IQ } \\
\hline b & \multicolumn{4}{|c|}{ Predictors: (Constant), IQ, MRTYPE } \\
\hline $\mathrm{c}$ & \multicolumn{4}{|c|}{ Predictors: (Constant), IQ, MRTYPE, AGE } \\
\hline d & \multicolumn{4}{|c|}{ Predictors: (Constant), IQ, MRTYPE, AGE, OHP } \\
\hline e & \multicolumn{4}{|c|}{ Predictors: (Constant), IQ, MRTYPE, AGE, OHP, SEX } \\
\hline
\end{tabular}

explained $36.0 \%$ of the variance in the model and the cumulative variance provided by all the predictors (IQ, Medical diagnosis, age, oral hygiene practice, sex) was $44.5 \%$.

Table 7 revealed that IQ, age, medical diagnosis, oral hygiene practice, and father's education were the most 
Table 7 Logistic regression: Odds ratio (OR) and 95\% confidence interval (CI) for caries, oral hygiene and periodontal status of mentally disabled individuals according to age, gender, education of father and mother, medical diagnosis, I.Q. level

\begin{tabular}{|c|c|c|c|}
\hline Independent Variable & $\begin{array}{l}\text { DMFT } \\
\text { OR }(95 \% \mathrm{CI})\end{array}$ & $\begin{array}{l}\text { Oral Hygiene Status (OHI-S) } \\
\text { OR }(95 \% \mathrm{CI})\end{array}$ & $\begin{array}{l}\text { Periodontal Status (CPI) } \\
\text { OR }(95 \% \mathrm{CI})\end{array}$ \\
\hline Age: Old vs. Young & $3.967(1.63-9.655)$ & $1.744(0.731-4.161)$ & $0.745(0.251-2.206)$ \\
\hline Sex: Male vs. Female & $1.093(0.523-2.288)$ & $0.833(0.401-1.731)$ & $0.800(0.284-2.252)$ \\
\hline $\begin{array}{l}\text { Father education: } \\
\text { Low vs. High }\end{array}$ & $1.514(0.781-2.936)$ & $0.753(0.237-2.398)$ & - \\
\hline $\begin{array}{l}\text { Mother education: } \\
\text { Low vs. High }\end{array}$ & - & $1.983(0.623-6.311)$ & $0.07573(0.021-0.273)$ \\
\hline I.Q: Severe vs. Mild & $6.768(2.895-15.825)$ & $10.872(3.724-31.739)$ & _ \\
\hline $\begin{array}{l}\text { Socioeconomic status: } \\
\text { Low vs.High }\end{array}$ & $2.149(1.00-4.619)$ & $0.628(0.280-1.412)$ & $0.06328(0.0159-0.251)$ \\
\hline $\begin{array}{l}\text { Mentally retarded type: } \\
\text { Down's syndrome vs. } \\
\text { Cerebral palsy }\end{array}$ & $2.766(1.487-5.145)$ & $2.943(1.491-5.806)$ & $2.060(0.922-4.601)$ \\
\hline $\begin{array}{l}\text { Oral hygiene practice: } \\
\text { Good vs.Poor }\end{array}$ & $2.980(1.409-6.302)$ & $0.336(0.150-0.752)$ & $0.125(0.0546-2.85)$ \\
\hline
\end{tabular}

important predictors for DMFT in addition to all other variables that maintained a statistically significant effect in the multivariate analysis. Thus, odds ratios for caries status were significantly higher among old than among young subjects, among those subjects having Down's syndrome as compared to cerebral palsy and among those subjects having severe retardation than mild retardation. A similar pattern was observed for oral hygiene status where odds ratios for poor oral hygiene status were significantly higher among subjects with poorly educated parents as compared to highly educated parents, among those subjects having Down's syndrome as compared to cerebral palsy, among those subjects having severe retardation than mild retardation and among those with less educated mothers. Table 7 also shows that odds ratios were significantly higher among subjects having Down's syndrome as compared to cerebral palsy. Down's syndrome was the most important predictor for poor periodontal status.

\section{Discussion}

Oral health and quality oral health care contribute to holistic health, which should be a right rather than a privilege (21). That is why individuals with disabilities deserve the same opportunities for dental services as those who are healthy. Therefore, this study was conducted to assess the impact of various socio-demographic and clinical variables on the oral health status of a mentally disabled population. It was evident that the caries experience of the disabled subjects who were attending 'special' schools was higher than that found in national oral health surveys of children in normal schools $(22,23)$ which also adhered to the WHO methodology. The present study reports a higher prevalence of untreated carious lesions in the disabled children than in their normal counterparts, thus agreeing with previous findings which suggested that the severity of caries attack is essentially the same in disabled and normal schoolchildren but that the rate of treatment is frequently lower in the disabled (24-26). This study showed that there was a high demand for provision of dental services, especially to the disabled, and that this population had received less dental treatment. Multiple logistic regression analyses revealed that the odds ratio for higher DMFT status was significantly higher among subjects with Down's syndrome than those with cerebral palsy at 2.766 (95\% CI 1.487-5.145). However, a study by Tannenbaum reported that caries occurrence was less frequent in children with Down's syndrome than in other mentally retarded or in healthy children (27).

Caries experience seems quite comparable with that seen in non-handicapped children of the same age. A study by Gizani et al. (28) showed a mean DMFT score of 2.9 versus 2.7 and a mean DMFS score of 4.7 versus 4.2 , respectively in 12-year-old children in Belgium. In our study, the mean DMFT and DMFS scores were less at 1.50 and 1.90 , respectively in $12-15$ year old children. From the epidemiological data available to date, there appears to be conflict regarding the caries susceptibility in children with Down's syndrome. Caries occurrence has been reported to be both higher $(29,30)$ and lower $(31,32)$ in subjects with Down's syndrome compared with nonDown's syndrome subjects or other individuals with mental retardation.

Furthermore, the proportion of subjects with no periodontal disease in the present population was observed to 
be $22.7 \%$ which is in strong disagreement with that of the general population of Rajasthan state, where the proportion of 12- and 15-year-old children without any signs of periodontal disease was $66.8 \%$ and $49.2 \%$, respectively. The mean number of healthy sextants in the study population was 1.71 for the age group 12-15, whereas in the children of the comparable ages in Rajasthan state it was found to be 3.7 (33). The mentally disabled subjects of the present study had a higher caries prevalence, poorer standard of oral hygiene and greater prevalence of periodontal disease than that found in normal children of comparable age groups. The mean oral hygiene index of the study population was $2.84 \pm 1.42$, whereas it was observed to be in the range of $1.1-1.7$ among school children (36). These results confirm the findings of other studies concerning the poor level of oral hygiene and high prevalence of periodontal disease among individuals with disabilities. $(26,34,35,37)$

The overall oral hygiene status of the study population was poor with a prevalence rate of $18.7 \%, 44.0 \%$ and $37.3 \%$ for good, fair and poor components, respectively, which was worse than that of a previous study conducted on handicapped children attending special schools in Birmingham, UK (38), where the corresponding values in hearing impaired children were 69\%, 29\% and 2\%, respectively. On the other hand, it was similar to a study by Oredugba which showed that $23 \%, 37 \%$ and $40 \%$ of the subjects had good, fair and poor oral hygiene status, respectively. Male subjects had poorer oral hygiene and periodontal status than their female counterparts as shown by the logistic regression analysis. Denloye (39) observed a similar trend among mentally retarded children of Nigeria, where higher OHI-S scores were recorded among males than females. High prevalence of periodontal disease and the greatest treatment needs were detected in subjects with Down's syndrome. This relatively high level of periodontal disease and treatment need in this group compared with normal and other disability groups confirmed previously reported data on the high prevalence of periodontal disease in populations with Down's syndrome. (13-15) Several investigators have reported a significant correlation between oral hygiene and periodontal conditions in children with Down's syndrome $(40,41)$.

Moreover, a high correlation between poor oral hygiene and the development and progression of periodontal disease has been well documented and the role of poor oral hygiene as a risk factor of periodontal diseases is well established (42). In multivariate analysis, both linear and logistic, the education level of mother and father was significantly associated with both caries and oral hygiene status. This could be explained by the findings from a study among children with Down's syndrome in Riyadh, which revealed that a higher percentage of children of illiterate mothers were found to use water only as a method of cleaning their teeth compared to other children (43), thus influencing the oral hygiene status. The commonly accepted frequency recommended by Frandsen et al. in 1986 for tooth brushing is twice a day (44). In this study, more than half of the subjects reported brushing at least twice a day. A considerable percentage $(41.2 \%)$ of the mildly mentally retarded and learning impaired children did not brush daily. Multiple logistic regression analyses revealed that the odds ratio for poor oral hygiene and periodontal status were significantly higher among Down's syndrome subjects than those with cerebral palsy at $2.943(1.491-5.806)$ and $2.060(0.922-$ 4.601 ), respectively. This observation confirmed previously reported data on the high prevalence of periodontal disease in populations with Down's syndrome $(14,45)$. The results have shown that poor oral health is a major problem for disabled schoolchildren, and the oral health of disabled children assessed seemed to indicate a cumulative neglect of oral health. The lack of regular dental care, which is available to normal schoolchildren, was reflected in the dental status of the disabled when their oral health was compared with that of normal schoolchildren. In comparison with normal children, the disabled subjects were not given enough dental care with respect to their treatment needs.

In conclusion, the oral health status of the present population was poor and was influenced by aetiology of the disability, IQ level, and parent's level of education. Oral health promotion programs should be aimed specifically at special needs schools and parents of disabled children. Oral health promotion should include facilitating access and regular use of oral health services. Taking into consideration the multi factorial influence on oral health status of the present disabled population, oral health promotion and intervention programs should be targeted and concentrated towards these risk groups.

\section{Acknowledgments}

We are thankful to Dr. H. R. Dayakara, Dr. K.T. Chandrasekhar and the Clinical Research Centre for their kind support.

\section{References}

1. Watson N (2000) Barriers, discrimination and prejudice. In: Disability and oral care, Nunn J ed, FDI World Dental Press, London, 15-28.

2. National Sample Survey Organization (2003) Disabled persons in India. NSS Report No. 485 (58/26/1), New Delhi. 
3. American Psychiatric Association (1994) Diagnostic and statistical manual of mental disorders. 4th ed, Washington.

4. Tesini DA, Fenton SJ (1994) Oral health needs of person with physical or mental disabilities. Dent Clin North Am 38, 483-498.

5. Hennequin M, Faulks D, Roux D (2000) Accuracy of estimation of dental treatment need in special care patients. J Dent 28, 131-136.

6. Boj JR, Davila JM (1995) Differences between normal and developmentally disabled children in a first dental visit. ASDC J Dent Child 62, 52-56.

7. Brandes DA, Wilson S, Preisch JW, Casamassimo PS (1995) A comparison of opinions from parents of disabled and non-disabled children on behavioral management techniques used in dentistry. Spec Care Dentist 15, 119-123.

8. Dicks JL (1995) Outpatient dental services for individuals with mental illness: a program description. Spec Care Dent 15, 239-242.

9. Glassman R, Miller CE, Lechowick J (1996) A dental school's role in developing a rural, community-based, dental care delivery system for individuals with developmental disabilities. Spec Care Dentist 16, 188-193.

10. Brown JP, Schodel DR (1976) A review of controlled surveys of dental disease in handicapped persons. ASDC J Dent child 43, 313-320.

11. Tesini DA (1980) Age, degree of mental retardation, institutionalization and socioeconomic status as determinants in the oral hygiene status of mentally retarded individuals. Community Dent Oral Epidemiol 8, 355-359.

12. Randell DM, Harth S, Seow WK (1992) Preventive dental health practices of non-institutionalized Down syndrome children: a controlled study. J Clin Pediatr Dent 16, 225-229.

13. Barnett ML, Press KP, Friedman D, Sonnenberg EM (1986) The prevalence of periodontitis and dental caries in a Down's syndrome population. J Periodontol 57, 288-293.

14. Desai SS (1997) Down syndrome: a review of the literature. Oral Surg Oral Med Oral Pathol Oral Radiol Endod 84, 279-285.

15. Cutress TW (1971) Periodontal disease and oral hygiene in trisomy 21. Arch Oral Biol 16, 1345-1355.

16. Gullikson JS (1973) Oral findings in children with Down's syndrome. ASDC J Dent child 40, 293297.

17. Forsberg H, Quick-Nilsson I, Gustavson KH, Jagell S (1985) Dental health and dental care in severely mentally retarded children. Swed Dent J 9, 15-28.

18. Reuland-Bosma W, van Dijk J (1986) Periodontal disease in Down's syndrome: a review. J Clin Periodontol 13, 64-73.

19. Greene JC, Vermillion JR (1964) The simplified oral hygiene index. J Am Dent Assoc 68, 7-13.

20. World Health Organization (1997) Oral health surveys: basic methods. 4th ed, WHO, Geneva, 3638.

21. Clark CA, Vanek EP (1984) Meeting the health care needs of people with limited access to care. J Dent Educ 48, 213-216.

22. Al-Mutawa S, Al-Duwairi Y, Honkala E, Honkala S, Shyama M (2002) The trends of dental caries experience of children in Kuwait. Dent News 9, 913.

23. Soparkar PM, Rose L, DePaola PF (2001) A comprehensive dental survey of Kuwaiti school children. Ministry of Health, State of Kuwait, 1-43.

24. Nunn JH, Murray JJ (1987) The dental health of handicapped children in Newcastle and Northumberland. Br Dent J 162, 9-14.

25. Storhaug K, Holst D (1987) Caries experience of disabled school-age children. Community Dent Oral Epidemiol 15, 144-149.

26. Mitsea AG, Karidis AG, Donta-Bakoyianni C, Spyropoulos ND (2001) Oral health in Greek children and teenagers, with disabilities. J Clin Pediatr Dent 26, 111-118.

27. Tannenbaum KA (1975) The oral aspects of mongolism. J Public Health Dent 35, 95-108.

28. Gizani S, Declerck D, Vinckier F, Martens L, Marks L, Goffin G (1997) Oral health condition of 12-yearold handicapped children in Flanders (Belgium). Community Dent Oral Epidemiol 25, 352-357.

29. Rosenstein SN, Bush CR Jr, Gorelick J (1971) Dental and oral conditions in a group of mental retardates attending occupational day centers. N Y State Dent J 37, 416-421.

30. Gupta DP, Chowdhury R, Sarkar S (1993) Prevalence of dental caries in handicapped children of Calcutta. J Indian Soc Pedod Prev Dent 11, 23-27.

31. Stabholz A, Mann J, Sela M, Schurr D, Steinberg D, Shapira J (1991) Caries experience, periodontal treatment needs, salivary $\mathrm{pH}$, and streptococcus mutans counts in a preadolescent Down syndrome population. Spec Care Dentist 11, 203-208.

32. Morinushi T, Lopatin DE, Tanaka H (1995) The relationship between dental caries in the primary dentition and anti S. mutans serum antibodies in children with Down's syndrome. J Clin Pediatr 
Dent 19, 279-284.

33. Bali RK, Mathur VB, Talwar PP, Chanana HB (2004) National oral health survey \& fluoride mapping. Dental Council of India, New Delhi, 105106.

34. Martens L, Marks L, Goffin G, Gizani S, Vinckier F, Declerck D (2000) Oral hygiene in 12-year-old disabled children in Flanders, Belgium, related to manual dexterity. Community Dent Oral Epidemiol 28, 73-80.

35. Seymen F, Aytepe Z, Kiziltan B (2002) Oral health status in children with Down syndrome. J Disabil Oral Health 3, 62-67.

36. Sogi GM, Bhaskar DJ (2002) Dental caries and oral hygiene status of school children in Davangere related to their socio-economic levels: an epidemiological study. J Indian Soc Pedod Prev Dent 20, 152-157.

37. Svatun B, Gjermo P (1978) Oral hygiene, periodontal health, and the need for periodontal treatment among institutionalized mentally subnormal persons in Norway. Acta Odont Scand 36, 89-95.

38. Shaw L, Maclaurin ET, Foster TD (1986) Dental study of handicapped children attending special schools in Birmingham, UK. Community Dent Oral Epidemiol 14, 24-27.
39. Denloye OO (1998) Oral hygiene status of mentally handicapped school children in Ibadan, Nigeria. Odontostomatol Trop 21, 19-21.

40. Sznajder N, Carraro JJ, Otero E, Carranza FA Jr (1968) Clinical periodontal findings in trisomy 21(mongolism). J Periodontol Res 3, 1-5.

41. Orner G (1976) Periodontal disease among children with Down's syndrome and their siblings. J Dent Res 55, 778-782.

42. Bellini HT, Campi R, Denardi JL (1981) Four years of monthly professional toothcleaning and topical fluoride application in Brazilian schoolchildren. I. Effect on gingivitis. J Clin Periodontol 8, 231-238.

43. Al-Hussyeen AA, Al-Sadhan SA (2006) Oral hygiene practices and dietary habits among children with Down's syndrome in Riyadh, Saudi Arabia. Saudi Dent J 18, 141-148.

44. Frandsen A (1986) Mechanical oral hygiene practices. State-of-the-science review. In: Dental plaque control measures and oral hygiene practices, Löe H, Kleinman DV eds, IRL Press, Washington, 93-116.

45. Barr-Agholme M, Dahllöf G, Modéer T, Engström PE, Engström GN (1998) Periodontal conditions and salivary immunoglobulins in individuals with Down's syndrome. J Periodontol 69, 1119-1123. 